\title{
Bioethanol used in Alkylation of Benzene over Modified ZSM-5 Catalysts with Nd and Pr
}

\author{
Parciulea AG ${ }^{1 *}$, Banu I $^{2}$, Bozga G ${ }^{2}$, Hubcă G ${ }^{2}$, Gaivoronschi B ${ }^{2}$ and Cincu C $^{2}$ \\ ${ }^{1}$ Ministry of Education, General Berthelot, Street no. 28-30, district 1, Bucharest, Romania \\ ${ }^{2}$ University Politechnica of Bucharest, Faculty of Applied Chemistry and Materials Science, Polizu 1-7, Bucharest, Romania
}

\begin{abstract}
Alkylation of benzene over new modified ZSM- 5 catalysts with Nd has been done in a metallic tubular reactor. The catalyst was synthesized from components modified with $\mathrm{NdCl} 3$ characterized by XR-Fluorescence Spectrometer, XRD apparatus, nitrogen adsorption analyzer and TGA for its acidity.

The alkylation experiments have been done at different reaction temperatures, pressures and benzene (ethylbenzene)/bioethanol molar ratio in order to establish their influence on the final composition of the reaction product, selectivity and conversion.

The results obtained with $\mathrm{Nd}$ modified catalyst were compared with those obtained from unmodified catalyst.
\end{abstract}

Keywords: Benzene alkylation; Ethylbenzene; Zeolitic catalyst; Bioethanol.

\section{Introduction}

The alkylation of benzene (B) with ethylene over ZSM-5 zeolite is an industrial process (Mobil Badger Process) for the synthesis of ethylbenzene (EB), an important raw material in manufacturing of polystyrene and other copolymers of styrene [1]. The use of ethanol (E) instead of ethylene for benzene or toluene alkylation has been reported in other paper [2-5]. For industrial scale is very important to replace ethylene or ethanol obtained from petrochemical processes with, "bioethanol" derived from biomass, a renewable raw material. The catalytic conversion of benzene to ethylbenzene or other chemicals with bioethanol over different types of zeolites or modified zeolite catalysts has been reported earlier [6-9]. Some interesting results with high selectivity for ethylbenzene in alkylation of benzene with ethanol using a zeolite catalyst modified with lanthanum were recently reported [10].

In this work, the results of the alkylation of benzene with bioethanol (96\% aqueous ethanol solution obtained from biomass) over a modified ZSM-5 zeolite with Nd cations as catalyst, were reported. We studied the influence of the catalyst, composition of the reaction mixture and alkylation process temperature, on the benzene conversion to ethylbenzene, diethylbenzene and other chemicals. Also, we compared the results obtained using the modified catalyst with $\mathrm{Nd}$ and the unmodified zeolite catalyst.

\section{Experimental Part}

\section{Materials}

All used chemicals were commercial (Merck, Aldrich) were of high purity reagents. Aqueous ethanol solution with $96 \%$ purity ("bioethanol" in our work) was separated by distillation from aqueous mixture obtained by fermentation of carbohydrates. The catalysts used in benzene alkylation with „bioethanol” were synthetized in the following steps [11-13].

Synthesis of ZSM-5 zeolite: The mixture of silice and alumina precursors with the molar composition $1.0 \mathrm{SiO}_{2} / 0.01 \mathrm{Al}_{2} \mathrm{O}_{3} / 1.2 \mathrm{Na}_{2} \mathrm{O} / 0.22 \mathrm{HDA}$ (hexametylene-diamine) was transformed into a microporous crystalline aluminosilicate in the presence of the binding agent (HDA). The hydrothermal synthesis was done in a stainless steel autoclave at $70-175^{\circ} \mathrm{C}, \mathrm{pH}=12$ for 48 hours and under continuous stirring. The product, Na-ZSM-5 was transformed into $\mathrm{NH}_{4}$-ZSM- 5 by ionic exchange with $1 \mathrm{M} \mathrm{NH}_{4} \mathrm{NO}_{3}$ solution and finally a zeolite as dry powder obtained $(Z)$.

Synthesis of zeolitic catalyst: The powder zeolite $\mathrm{NH}_{4}-\mathrm{ZSM}-5(60 \%)$, alumina (40\%) as a binder and nitric acid (as 10\% aqueous solution) were mixed to obtain a paste. This paste was transformed into cylinders $(\theta=2 \mathrm{~mm}, \mathrm{~L}=5 \mathrm{~mm})$ using a plunger-type extruder and the catalyst was dried $\left(80^{\circ} \mathrm{C}, 8\right.$ hours $)$ and calcined $\left(550^{\circ} \mathrm{C}, 6\right.$ hours, $\left.2^{\circ} \mathrm{C} / \mathrm{min}\right)$ to obtain the final form of $\mathrm{H}-\mathrm{ZSM}-5(\mathrm{ZC})$.

The chemical modification of the catalyst (ZC) was achieved by impregnation with $0.1 \mathrm{M} \mathrm{NdCl}_{3}$ aqueous solution, dried at $80^{\circ} \mathrm{C}$ and calcined at $500^{\circ} \mathrm{C}$ to obtain $\mathrm{ZC}-\mathrm{Nd}$ catalyst.

CharacterizationofZ,ZC,andZC-Ndcatalysts:Chemicalcomposition of H-ZSM-5 was established using an XR-Fluorescence Spectrometer -S8Tiger. Crystallinity and phase purity were confirmed by X-ray diffraction (XRD apparatus X'Pest PRO-MPD, PANalytical).

Nitrogen adsorption isotherms were measured at $77^{\circ} \mathrm{K}$ on a Micrometrics ASAP 2010 volumetric adsorption analyzer. The specific surface area was calculated by the BET method and for diameter of the pores was used the BJM method.

The acidity of the catalyst was determined by temperature programmed desorption (TPD) of diethylamine (DEA). Thermogravimetric analysis (TGA) was performed with a Du Pont Instrument device, “Thermal Analyst 2000/2100" coupled to a module 951 Thermogravimetric Analyzer. Desorption of the DEA was carried out by heating the sample from $20^{\circ} \mathrm{C}$ to $600^{\circ} \mathrm{C}$ in nitrogen atmosphere with $10^{\circ} \mathrm{C} / \mathrm{min}$.

*Corresponding author: Parciulea AG, Ministry of Education, General Berthelot Street no. 28-30, district 1, Bucharest, Romania, Tel: 021-4056383; E-mail: parciuleaanca@yahoo.com

Received May 22, 2015; Accepted May 23, 2015; Published June 01, 2015

Citation: Parciulea AG, Banu I, Bozga G, Hubcă G, Gaivoronschi B, et al. (2015) Bioethanol used in Alkylation of Benzene over Modified ZSM-5 Catalysts with Nd and Pr. Chem Sci J 6: 96. doi:10.4172/2150-3494.100096

Copyright: (c) 2015 Parciulea AG, et al. This is an open-access article distributed under the terms of the Creative Commons Attribution License, which permits unrestricted use, distribution, and reproduction in any medium, provided the original author and source are credited. 
Citation: Parciulea AG, Banu I, Bozga G, Hubcă G, Gaivoronschi B, et al. (2015) Bioethanol used in Alkylation of Benzene over Modified ZSM-5 Catalysts with Nd and Pr. Chem Sci J 6: 96. doi:10.4172/2150-3494.100096

Page 2 of 4

\section{Alkylation reaction}

The alkylation reaction was performed in a metallic reactor (Figure 1). Details about the reactor have been reported earlier $[11,13]$. The experiments were done at $250-450^{\circ} \mathrm{C}$ with different molar ratio $\mathrm{B} / \mathrm{E}$ $(1 / 1,2 / 1$ and $3 / 1)$ at 2 bar pressure and at feeding flow rate of $2.5 \mathrm{~mL} /$ $\mathrm{min}$. The nitrogen was used as carrier gas $(30 \mathrm{~mL} / \mathrm{min})$. The reaction mixture was analyzed by gas chromatography to establish its chemical composition (Varian CP3800 apparatus coupled with MS Varian 4000)

\section{Results and Discussion}

The properties of $\mathrm{H}-\mathrm{ZSM}-5$ zeolite powder (Z), $\mathrm{H}-\mathrm{ZSM}-5 / \mathrm{Al}_{2} \mathrm{O}_{3}$ (ZC) and , $\mathrm{H}-\mathrm{ZSM}-5 / \mathrm{Al}_{2} \mathrm{O}_{3}$ modified with $\mathrm{Nd}(\mathrm{ZC}-\mathrm{Nd})$ materials are presented in the (Table 1). We selected a H-ZSM-5 with the ratio $\mathrm{SiO}_{2} /$ $\mathrm{Al}_{2} \mathrm{O}_{3} \approx 100$ according to the results presented in the literature [3]. This type of catalyst gives a high selectivity for EB in alkylation process of benzene with ethanol. For ZC catalyst BET surface area and pores volume are smaller than for $\mathrm{Z}$ zeolite because $\mathrm{Al}_{2} \mathrm{O}_{3}$ used as binder is a messoporous material. There are not important modifications when $\mathrm{ZC}$ is transformed into ZC-Nd catalyst (Table 1). The XRD analysis of zeolitic material (Z) showed (Figure 2) a well crystallized material with specific MFI lattice [14].

The values of acid strength (the loss with temperature of DEA in $\mathrm{mE} / \mathrm{g}$ catalyst ) for ZC and ZC-Nd catalysts are presented in Table 1 and on the (Figures 3 and 4). There are three delimited zones (A, B, C) on the graphs which are assigned to the week, medium and strong acidity. The presence of the Nd cations reduces the total acidity (increased loss of DEA) and will influence its activity in alkylation process. The chemical composition (\%) of the reaction mixtures (benzene, ethylbenzene, diethylbenzene-DEB, xylene-X, trimethylbenzene$\mathrm{TMB}$, methylethylbenzene- MEB) using $\mathrm{ZC}$ and $\mathrm{ZC}-\mathrm{Nd}$ catalysts are presented on the (Figures 5-7).

Lanthanides (including Pr, Nd) have electrons in " $\mathrm{f}$ " sheath (layer) which gives the possibility to form complexes and high catalytic activity in chemical reaction as benzene alkylation. From those results we observe a reduction of benzene reactivity (increased concentration

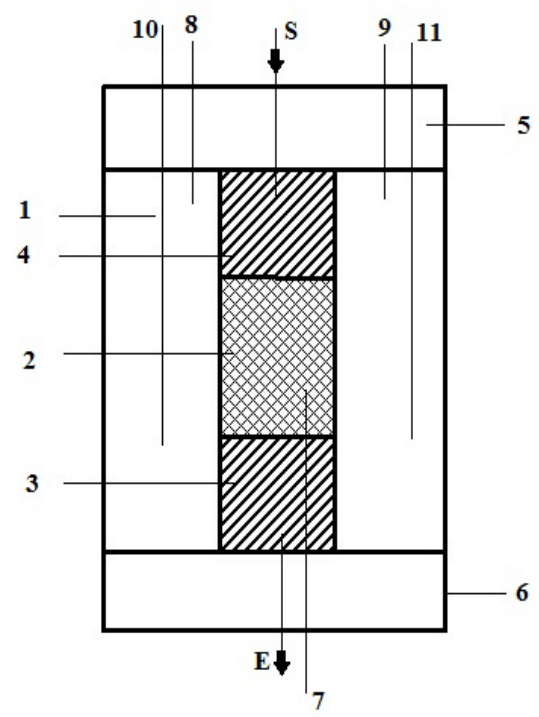

Figure 1: Alkylation reactor 1) Reactor body 2) Catalyst zone 3) Inert zones 4 ) Inert zones 5) Flanges 6) Flanges 7-11) Thermocouples, S: Reaction mixture supply, E: Exit of reaction products

\begin{tabular}{|c|c|c|c|}
\hline Properties & $\mathbf{Z}$ & ZC & ZC-Nd \\
\hline $\mathrm{SiO}_{2}, \mathrm{~mole} \%$ & 8.6 & & \\
\hline $\mathrm{Al}_{2} \mathrm{O}_{3}, \mathrm{~mole} \%$ & 1.03 & & \\
\hline $\mathrm{Na}_{2} \mathrm{O}, \mathrm{mole} \%$ & 0.37 & & \\
\hline $\mathrm{SiO}_{2} / \mathrm{A}_{2} \mathrm{O}_{3}$, mole $/ \mathrm{mole}$ & 96 & & \\
\hline Pores diameter, nm & & 3.51 & 3.40 \\
\hline BET surface area, $\mathrm{m}^{2} / \mathrm{g}$ & 410 & 300 & 291 \\
\hline Micropores surface area, $\mathrm{m}^{2} / \mathrm{g}$ & 255 & 170 & \\
\hline Total volume pores, $\mathrm{cm}^{3} / \mathrm{g}$ & 0.323 & 0.103 & 0.100 \\
\hline Micropores volume, $\mathrm{cm}^{3} / \mathrm{g}$ & 0.357 & 0.089 & \\
\hline Nd content, \% & & & 3.01 \\
\hline $\begin{array}{l}\text { Acidity (loss of DEA) }\left(\mathrm{mE}_{\mathrm{g}} \mathrm{DEA} / \mathrm{g}\right) /(\%) \\
\text { Total }\end{array}$ & & $0.486 / 100$ & $0.685 / 100$ \\
\hline Weak & & $0.206 / 42.5$ & $0.378 / 55.2$ \\
\hline Medium & & $0.164 / 33.7$ & $0.165 / 24.1$ \\
\hline Strong & & $0.116 / 23.8$ & $0.142 / 20.7$ \\
\hline
\end{tabular}

Table 1: Properties of the catalysts: Z, ZC and ZC-Nd.

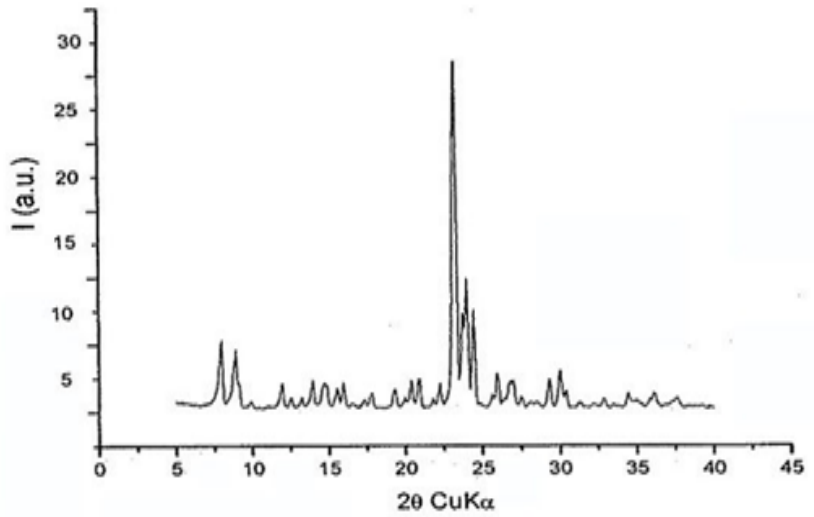

Figure 2: XRD diffractogram for ZSM-5 zeolite synthesized in the presence of hexamethylenediamine.

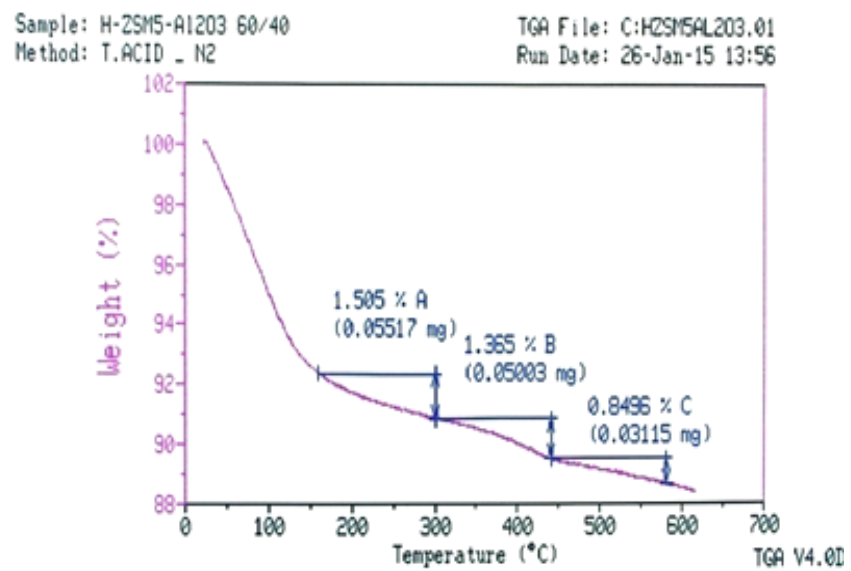

Figure 3: The loss of DEA with temperature for ZC catalyst.

of unreacted benzene) in alkylation process in the presence of ZC-Nd catalyst in comparison with ZC catalyst.

We suppose that this phenomenon is explained by the reduction of the total acidity of $\mathrm{ZC}-\mathrm{Nd}$ catalyst due to the adsorption of $\mathrm{Nd}$ cations on the acid centers. The ionic radius of $\mathrm{Nd}^{3+}$ is $\approx 0.995 \AA$, so it can enter into all micropores (diameter $=3.40 \mathrm{~nm}$, Table 1$)$ of the catalyst. 
Citation: Parciulea AG, Banu I, Bozga G, Hubcă G, Gaivoronschi B, et al. (2015) Bioethanol used in Alkylation of Benzene over Modified ZSM-5 Catalysts with Nd and Pr. Chem Sci J 6: 96. doi:10.4172/2150-3494.100096

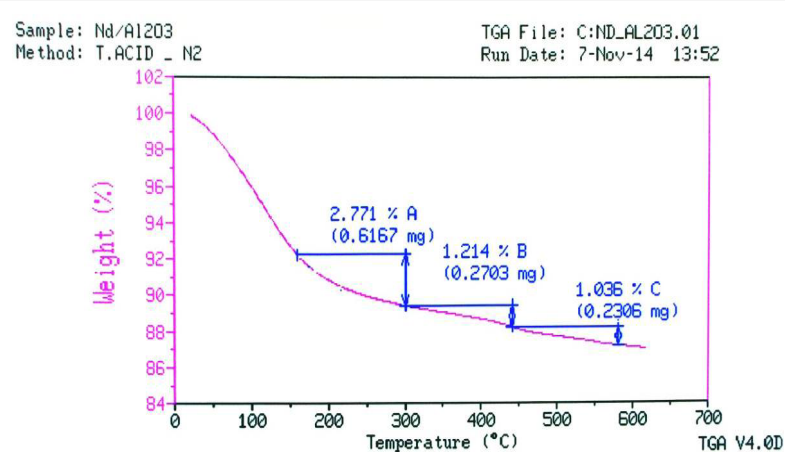

Figure 4: The loss of DEA with temperature for ZC-Nd catalyst.

$\mathrm{B} / \mathrm{E}=1 / 1 \mathrm{~mole} / \mathrm{mole}$

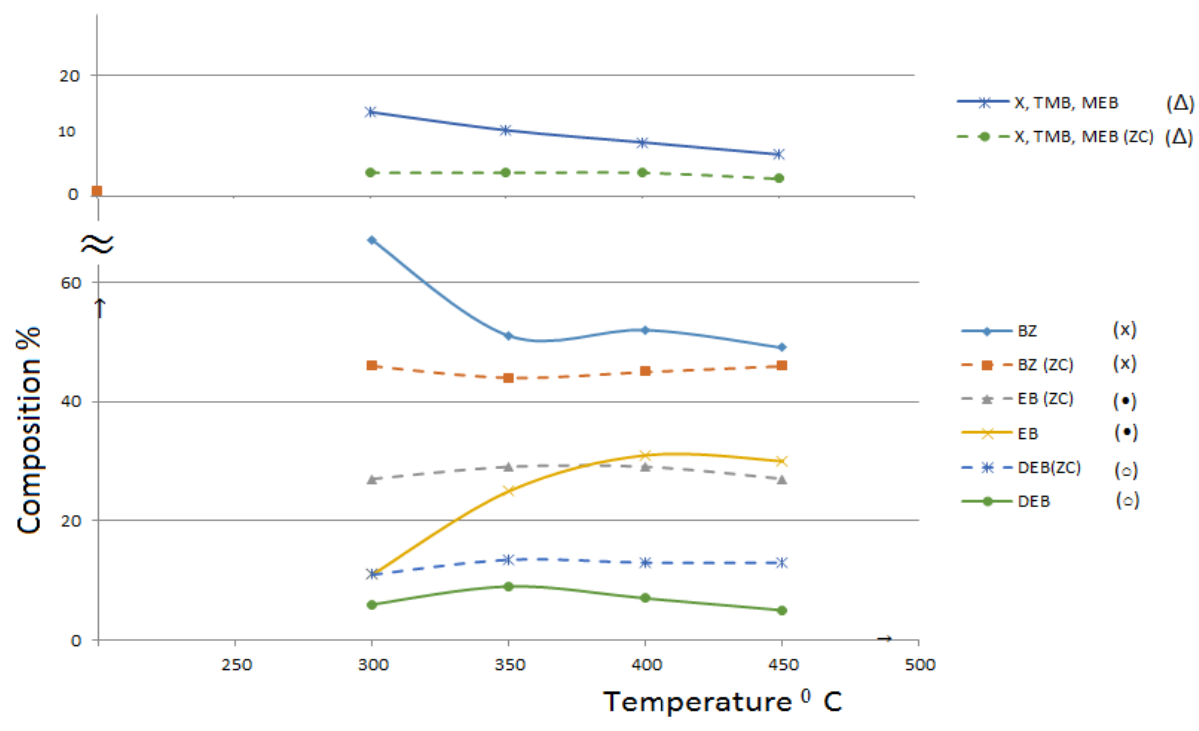

$\mathrm{B}(\mathrm{X})$; EB $(\cdot)$; DEB $(0) ; \mathrm{X}+\mathrm{TMB}+\mathrm{MEB}(\Delta)$

Figure 5: Concentration of the components in reaction mixture as a function of the temperature catalysts ZC (----) and ZC-Nd ( $\_$).

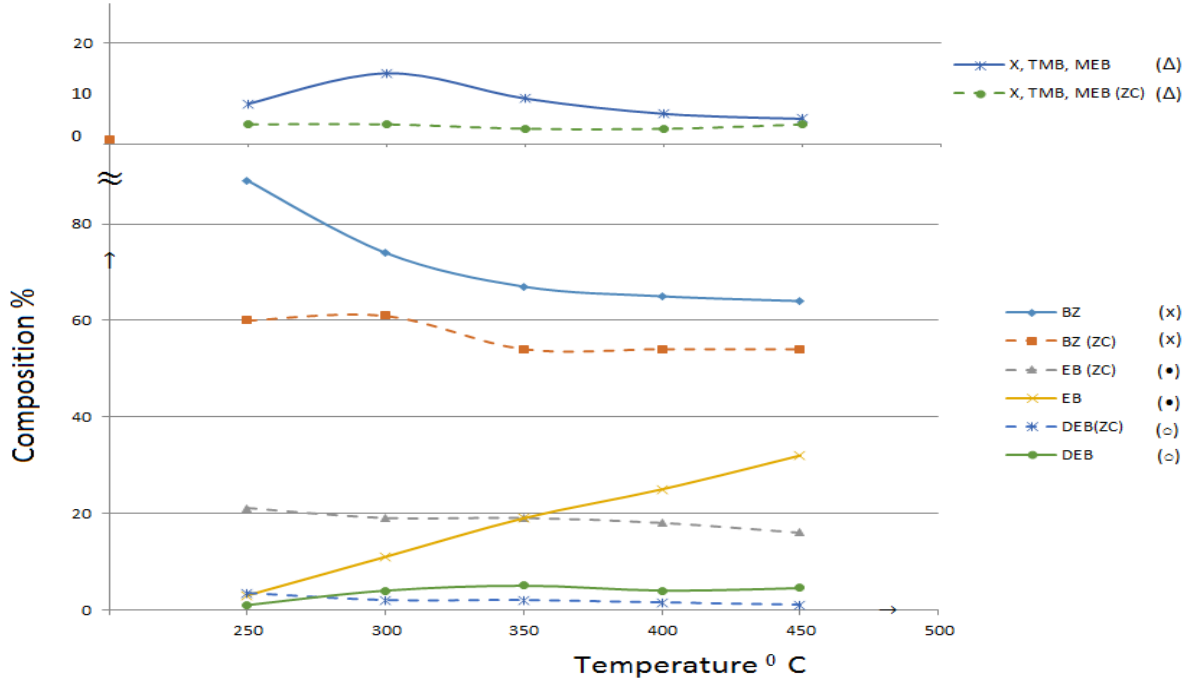

$\mathrm{B} / \mathrm{E}=2 / 1 \mathrm{~mole} / \mathrm{mole}$

$\mathrm{B}(\mathrm{X})$; EB $(\bullet) ; \mathrm{DEB}(\mathrm{o}) ; \mathrm{X}+\mathrm{TMB}+\mathrm{MEB}(\Delta)$

Figure 6: Concentration of the components in reaction mixture as a function of the temperature catalysts ZC (-----) and ZC-Nd ( $\_$). 
Citation: Parciulea AG, Banu I, Bozga G, Hubcă G, Gaivoronschi B, et al. (2015) Bioethanol used in Alkylation of Benzene over Modified ZSM-5 Catalysts with Nd and Pr. Chem Sci J 6: 96. doi:10.4172/2150-3494.100096

$\mathrm{B} / \mathrm{E}=3 / 1 \mathrm{~mole} / \mathrm{mole}$

$\mathrm{B}(\mathrm{X})$; EB $(\cdot) ; \mathrm{DEB}(\mathrm{o}) ; \mathrm{X}+\mathrm{TMB}+\mathrm{MEB}(\Delta)$

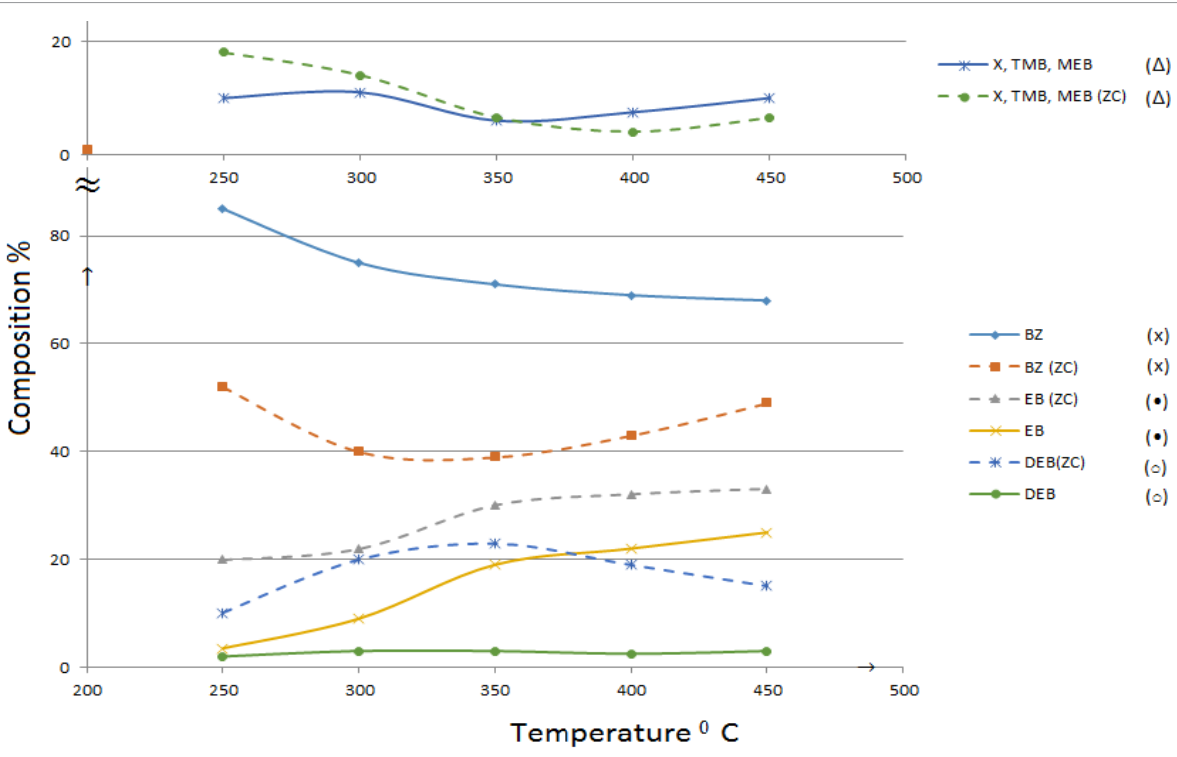

Figure 7: Concentration of the components in reaction mixture as a function of the temperature catalysts ZC (----) and ZC-Nd ( $\_$).

The concentration of $\mathrm{EB}$ in reaction mixture increases with temperature in the region $\left(250-450^{\circ} \mathrm{C}\right)$ for all ratios $\mathrm{B} / \mathrm{E}$. The modified catalyst with $\mathrm{Nd}$ gives a better result increased concentration of $\mathrm{EB}$ in comparison with $\mathrm{ZC}$ catalyst only for the ratio $\mathrm{B} / \mathrm{E}=2 / 1 \mathrm{~mole} / \mathrm{mole}$ at $350-450^{\circ} \mathrm{C}$. In the case of mixture $\mathrm{B} / \mathrm{E}=3 / 1 \mathrm{~mole} / \mathrm{mole}$ the catalyst $\mathrm{ZC}$ $\mathrm{Nd}$ is more selective for DEB than ZC-catalyst (Figure 7 curves DEB and DEB-ZC).

\section{Conclusions}

1. The synthesized zeolitic material $\mathrm{Z}$ has a well crystallized structure with specific MFI lattice.

2. Chemical modification of $\mathrm{ZC}$ catalyst with $\mathrm{Nd}$ cations decreases its acidity and reactivity of benzene in alkylation process;

3. For both catalysts (ZC and ZC-Nd) the concentration of $\mathrm{EB}$ in reaction mixture increases with temperature between $250^{\circ} \mathrm{C}-450^{\circ} \mathrm{C}$ for all ratios $\mathrm{B} / \mathrm{E}$;

4. The catalyst ZC-Nd gives a reaction mixture with a higher concentration in $\mathrm{EB}$, than $\mathrm{ZC}$ catalyst only in a particular case: $\mathrm{B} / \mathrm{E}=2 / 1 \mathrm{~mole} / \mathrm{mole}$ and $\mathrm{T}=350^{\circ} \mathrm{C}-450^{\circ} \mathrm{C}$;

5. In the case of initial mixture $\mathrm{B} / \mathrm{E}=3 / 1 \mathrm{~mole} / \mathrm{mole}$, the catalyst ZC-Nd has a higher selectivity for DEB than ZC catalyst.

\section{References}

1. Dwyer FG, Lewis PJ, Schneider FM (1976) Chem Eng 83: 90.

2. Yuan JJ, Gevert BS (2006) Alkylation of benzene with aqueous solution of ethanol over ZSM-5 catalysts. Indian Journal of Chemical Technology 13: 334 340.

3. Yuan JJ, Gevert BS (2004) Alkylation of benzene with ethanol over ZSM5 catalyst with different $\mathrm{SiO} / \mathrm{Al} 2 \mathrm{O} 3$ ratios. Indian Journal of Chemical Technology 11: 337.

4. Dandekor AB, Degnon TF, Mc Williams JP, Venkat CR (2003) US Patent.

5. Bhat YS, Dos J, Halgeri AB (1995) Coke Induced Stabilization of Catalytic Activity of Silylated ZSM-5 Zeolite. J Catal 155: 154.

6. Sridevi U, Bhashar Rao BK, Pradhan NC (2001) Kinetics of alkylation of benzene with ethanol on AICl3-impregnated 13X zeolites. Chem Eng J 83: 185

7. Walendziewski J, Trawczynski J (1996) Alkylation of Toluene with Ethanol. Ind Eng Chem Res 35: 3356.

8. Sabu KR, Rao KVC, Nair CGR (1994) Alkylation of Benzene, Toluene and Xylene Isomers with C-2, C-3 and C-4 Aliphatic-Alcohols pn Tio2-Sio2-Al2o3 and Moo3-Sio2-Al2o3 Catalysts. Indian J Chem 33B: 1053.

9. Loredano L, Bencini E, Casalini A (2012) Process for the alkylation of benzene with ethanol or mixtures of ethanol and ethylene. Brevet EP 20100728287/12.

10. Li JH, Nan WY, Jun H, Zhirong Z (2012) Alkylation of Benzene with Ethanol on Zeolites Modified with La2O3. Advanced Materials Research 347-353: 3670.

11. Parciulea AG, Hubcă G, Cincu C (2013) Alkylation of benzene with bioethanol on modified zeolitic catalyst. Materiale Plastice 50: 167-170.

12. Parciulea AG, Hodosan C, Nistor L, Hubcă G, Cincu C (2014) Revista Chimie (Bucharest) 65: 590.

13. Final report of Contract 861/26.11.2010 Biosint EB SRL -ANCS, Bucharest, Romania.

14. Baerlocher CH, Meier WM, Olson DH (2001) “Atlas of Zeolite From work Types" the fifth

15. Revised (edn) Elsevier Science, UK 